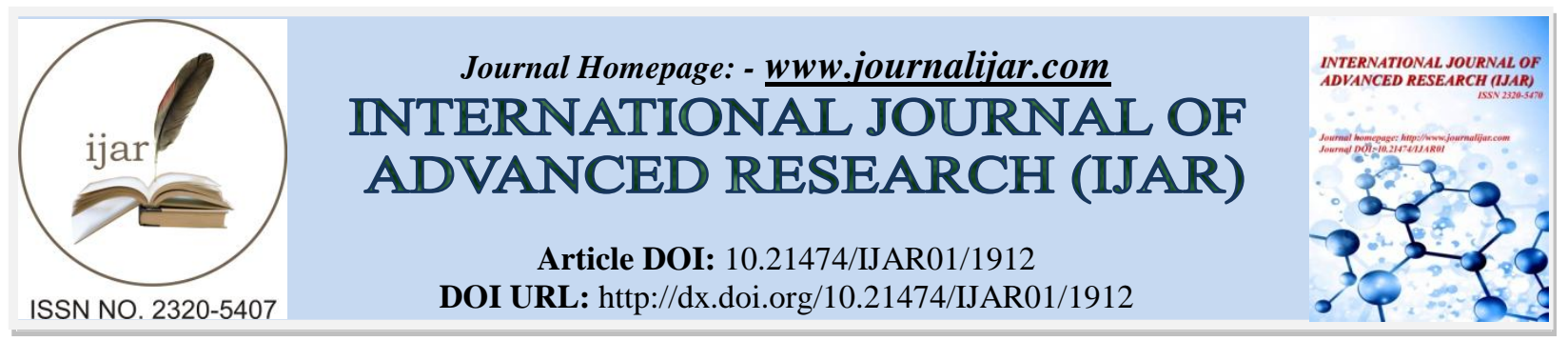

RESEARCH ARTICLE

\title{
EFFECT OF SURYANAMASKARA ON WRIST JOINT FLEXIBILITY IN SCHOOL GOING CHILDREN.
}

\begin{abstract}
Anil Mili.
Assistant Professor, Department of Physical Education, Rajiv Gandhi University,Rono Hills Doimukh, Arunachal Pradesh.
\end{abstract}

\section{Manuscript Info}

Manuscript History

Received: 12 August 2016

Final Accepted: 22 September 2016

Published: October 2016

Key words:-

Goniometer, Suryanamaskara,Wrist

Joint Flexibility.

\section{Abstract}

The Objective of this study was to determine the effects of Suryanamaskara on Wrist joint flexibility in school going children. The subjects for this study were selected from the male students of Government Higher Secondary School, Anini, Arunachal Pradesh. A total of 30 boys were selected and used as one experimental group (15) and other control group (15). Flexibility was measured in degrees using a Goniometer. Training was given up to sixty days, 5 times in week, each session scheduled for 60 minutes. The Pre-Test and PostTest randomized group design was used for the purpose of this study. The test was administered and the record were analysed before the training program and after the completion of the treatment again the test was administered on the subjects and results were analysed. ANCOVA was used to find the significant effects of Suryanamaskara on flexibility in school going children at 0.05 levels of significance. In relation to wrist joint Flexibility, effect of Suryanamaskara was found significant.

Copy Right, IJAR, 2016,. All rights reserved.

\section{Introduction:-}

The importance of yoga in today's world cannot be overlooked by merely terming yoga as one form of exercise. We must understand yoga as a form of remedy to various kinds of psycho-physiological weaknesses of our body. Various forms of yoga helps in improvement and control over an individual's mind, body and soul leading to peaceful physical and mental state. Gradually, yoga has taken over the traditional system of treatment of various ailments. People of developed countries these days also, have taken up yogic knowledge for treatment and management of life threatening health issues.

Flexibility of joints is one of the most important aspects and an indicator of good health condition of an individual. Various research papers on yoga have indicated positive effective of yogic exercises on various systems of our body. Yoga practice to a great extent increases the range of motion and flexibility of joints. For the true benefits of yoga to take place, regular practice and application yogic knowledge is very important in day to day life.

\section{Methods:-}

Selection of Subjects: 30 malestudents of Government Higher Secondary School, Anini, Arunachal Pradesh were selected at random as subjects for the study and divided into two groups of 15 subjects each. All subjects belonged 
to almost from the same socio economic group and were found to be physically fit for the type of programme they were selected. The subjects were divided into two groups (experimental group and control group) at random by drawing lots. The age of these subjects range between 12 to 16 years. All of them were taking part in routine physical activity programme as per the classes of the school.

\section{Selection of Variable:-}

Wrist joint Flexibility was selected as variable or the study and it was measured in degrees by Goniometer.

\section{Experimental Design:-}

Pre-test and post-test randomized group design was employed for the study.

\section{Procedure for Administration of the Test:-}

After selecting the students, they were recorded for Flexibility ofwrist joint, which was measured with help of Goniometer in degrees. After collecting the initial data, the subjects were administrated two months training schedule, which was the practice of Suryanamaskara for three day per week for duration of 60minutes. And after the sixty days, flexibility of wrist joint was again recorded by Goniometer in degrees.

\section{Training and Practice of Suryanamaskara:-}

The training of Suryanamaskara to the experimental group was given in the Auditorium Hall of Government Higher Secondary School, Anini Arunachal Pradesh. The practice session was conducted for a period of 60 minutes in the morning 6.00AM to 7.00 AM every Monday to Friday for duration of sixty days.

\section{Statistical Procedure:-}

To find out the significant difference between different pair means, the 'ANCOVA'was used. The level of significance was set at 0.05 .

\section{Results:-}

Table 1:- Adjusted post test means of experimental group and control group in relation to wrist joint flexibility

\begin{tabular}{|l|c|c|c|}
\hline Groups & Mean & SD & N \\
\hline Suryanamaskara & 78.01 & 5.19 & 15 \\
\hline Control Group & 74.13 & 9.55 & 15 \\
\hline
\end{tabular}

Table 1 revealed that, there were 15 subjects in both the groups. The mean and standard deviation of uryanamaskara group and control group was $78.01 \pm 5.19$ and $74.13 \pm 9.55$ respectively.

Figure 1:- Adjusted Post Test Means of Experimental Group and Control Group In Relation to Wrist Joint Flexibility.

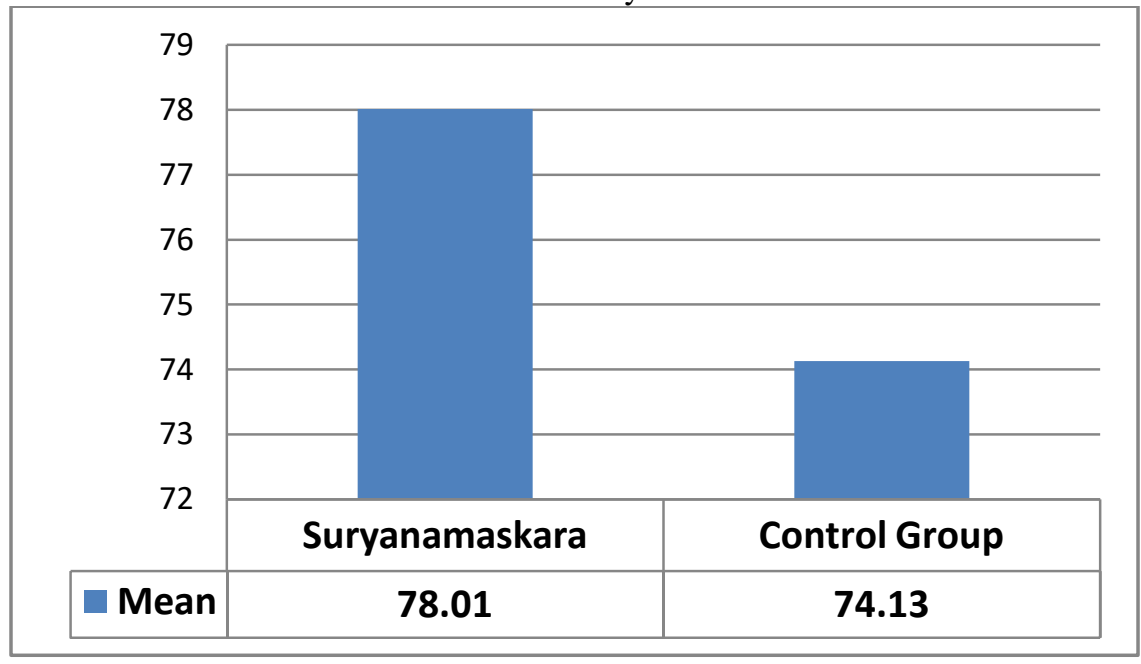


Table 2:- Analysis of Co-Variance for comparison of Adjusted Post Test Means of Experimental group and control group in Flexibility of wrist joint.

\begin{tabular}{|l|c|c|c|c|c|}
\hline & SS & df & MSS & F & p-value \\
\hline Contrast & 195.270 & 1 & 195.270 & 89.670 & .000 \\
\hline Error & 58.797 & 27 & 2.178 & & \\
\hline
\end{tabular}

*Significant at .05 level

Table 2 revealed that the obtained ' $F$ ' value 89.670 was found significant at 0.05 level in case of wrist joint flexibility, since this value was found higher than the tabulated value 4.20 at $1,27 \mathrm{df}$.

\section{Discussion:-}

Finally after collection and compilation of data, detailed statistical analysis was conducted using ANCOVA. The research scholar examined the effect of Suryanamaskara on wrist joint flexibility in school going children. The results in general, supported that regular practice of Suryanamaskara enhances and improves the wrist joint flexibility among the school going children. The ranges of movement in the experimental group were found to be significantly improved. The rate of improvement was higher for the experimental groups in comparison to the control groups. Final, results show that the participants who followed the treatment of Suryanamaskara improved their wrist joint flexibility higher than participants in control group.

\section{References:-}

1. Bal, B.S. and Kaur, P.J. (2009). Effects of selected Asanas in hatha yoga on agility and flexibility level. Journal of Sport and Health Research. 1(2):75-87.

2. Chakarborty, Jishu(1995). Abstract from International Conference on Health, Sports and Physical Fitness; Need For Integrated Approach.

3. Cureton, Krik Thomas, Encyclopedia Of Physical Education Fitness and Sports Salt Lake City Utah : Brighten Publishing Co.

4. Daniel, J. Neppel (1968).A Study of the Change Caused By Modern Dance Movement on Flexibility and Balance of College Freshman Football Players. Completed Research in Health, Physical Education and Recreation, 10.

5. De Vries, A. Herbert (1980). Evaluation of Static Stretching Procedure for Improvement of Flexibility. Research Quarterly, 3: 222-229

6. Sider(1984). Evaluation of Strength and Flexibility of Hip Joint. Dissertation Abstract International, 35 : 3494

7. Bridell E. Gary (1970). A Comparison of Selected Static and Dynamic Stretching Exercise on the Flexibility of the Hip Joint". Completed Research in Health, Physical Education and Recreation, 12: 74.

8. Johnson, Barry L. and Nelson, Jack K. (1986). Practical Measurement for Evaluation in Physical Education.USA: Burgrers Publishing Corporation.

9. Mathews,Donald K. (1979). Measurement in Physical Education. Philadelphia:W.B. Saunders Co.

10. Denial J. Amin(2013), The effects of selected Asanas in Iyengar yoga on flexibility: Pilot study. Journal of bodywork and movement therapies online.

11. Gharote and Ganguly, K.S. (1973). Effect of yogic training on physical fitness. Yoga Mimamsa, XV. 